\title{
Molluscicidal activity of Nerium indicum bark
}

SushmaSingh and D.K. Singh

\author{
Department of Zoology, DDU University of Gorakhpur, \\ Gorakhpur, UP, India
}

\section{Correspondence \\ D.K. Singh \\ Department of Zoology DDU University of Gorakhpur Gorakhpur 273 009, UP India \\ Research supported by Uttar Pradesh Council of Science and Technology, UP (No. CST/SERC/ZOOL/1/96).}

Received March 12, 1997 Accepted March 17, 1998

\section{Abstract}

The molluscicidal activity of Nerium indicum bark against Lymnaea acuminata snails was studied. The toxicity of different bark preparations was both time and dose dependent. The $24-\mathrm{h} \mathrm{LC}_{50}$ of the lyophilized aqueous extract of bark was $34.5 \mathrm{mg} / \mathrm{l}$ whereas that of lyophilized boiled water extract was $42.5 \mathrm{mg} / \mathrm{l}$. Low concentrations of Key words - Nerium indicum - Plant molluscicide - Lymnaea acuminata vacuum-dried ethanolic extract (24-h $\left.\mathrm{LC}_{50}: 4.9 \mathrm{mg} / \mathrm{l}\right)$ and purified bark (24-h $\left.\mathrm{LC}_{50}: 0.87 \mathrm{mg} / \mathrm{l}\right)$ were effective in killing the test snails.

The snail Lymnaea acuminata is the intermediate host of the flukes Fasciola hepatica and $F$. gigantica which cause endemic fascioliasis in the northern part of India $(1,2)$. One of the major preventive steps against fascioliasis is the control of the vector snail population. Synthetic and natural molluscicides have played a significant role in restricting the population of the snail Lymnaea acuminata $(2,3)$. Bioactive products of plant origin have become the focus of attention because they are less expensive and less hazardous to the environment than their synthetic counterparts. Singh et al. (4) have reported that the latex of Nerium indicum is highly effective in killing the snail $L$. acuminata. In the present study bark of the plant Nerium indicum Miller (Apocynaceae) was tested against L. acuminata to explore the full potential use of different parts of this plant as a molluscicide.

Nerium indicum bark was collected from the departmental garden from July to September 1996 and identified by Prof. S.K. Singh (taxonomist), Botany Department, University of Gorakhpur, where voucher (No. 1706) is on deposit. Different preparations were obtained from Nerium indicum bark for the toxicity study.

Lyophilized aqueous bark extract. Small pieces of $5 \mathrm{~g}$ dried bark were crushed with a mortar and pestle and extracted with $100 \mathrm{ml}$ water. These extracts were centrifuged at $1000 \mathrm{~g}$ and the supernatant was lyophilized. A total of $180 \mathrm{mg}$ dry powder was obtained, which was used for the toxicity experiment.

Lyophilized boiled bark extract. The supernatant of the aqueous bark extract was prepared as described above and boiled for 5 min. The boiled water was allowed to cool and lyophilized. The $167 \mathrm{mg}$ dry powder so obtained was tested for molluscicidal activity.

Ethanolic bark extract. Small pieces of dried bark were pulverized in a grinder. Ten grams powder was extracted with $250 \mathrm{ml}$ $95 \%$ ethanol at room temperature overnight. Ethanol was evaporated under vacuum and the remaining $1.3 \mathrm{~g}$ dried parts were used for the determination of molluscicidal activity.

Purified bark. Forty milliliters of ethanolic (95\%) bark extract was subjected to Silica gel (60-120 mesh, Qualigens Glass, Precious Electrochemindus Private Limited, Bombay, 
India) column chromatography (5 x $45 \mathrm{~cm})$. Five-milliliter fractions eluted with ethyl alcohol (95\%) were collected. Ethyl alcohol was evaporated under vacuum and the remaining parts were used for the determination of molluscicidal activity.

Test animals, Lymnaea acuminata $(2.25$ $\pm 0.2 \mathrm{~cm}$ long), were collected locally and allowed to acclimate for $72 \mathrm{~h}$. Toxicity experiments were performed by the method of Singh and Agarwal (5). Ten animals were kept in a glass aquarium containing 3 liters of dechlorinated tap water. Snails were exposed to different doses of different preparations and fractions obtained by column chromatography of Nerium bark to observe the toxicity for 24, 48, 72 and $96 \mathrm{~h}$. The weight of the lyophilized aqueous bark extract, vacuum-dried ethanolic extract and the purified components obtained from the column was taken as the final strength per liter of aquarium water. Control animals were exposed to an equal volume of dechlorinated water. The toxicity of these preparations was also tested against Colisa fasciatus fish.

Mortality was recorded every $24 \mathrm{~h}$ up to $96 \mathrm{~h}$ and dead animals were removed immediately so that other test animals were prevented from being contaminated. Lethal concentration $\left(\mathrm{LC}_{50}\right)$ values, upper and lower confidence limits and slope values were calculated according to the method of Russell et al. (6). The product moment correlation coefficient was determined between exposure time and different $\mathrm{LC}_{50}$ values (7).

Table 1 shows that the toxicity of different preparations of Nerium indicum bark against Lymnaea acuminata was time and dose dependent. The $24-\mathrm{h} \mathrm{LC}_{50}$ of the lyophilized aqueous extract and the dried pow-

Table 1 - Toxicity of Nerium indicum bark against the snail Lymnaea acuminata.

Batches of 10 snails were exposed to different extracts of Nerium indicum bark and column-purified ethanolic extract. Mortality was determined every $24 \mathrm{~h}$. Each set of experiments was replicated six times. The values are the final concentrations $(\mathrm{w} / \mathrm{v})$ in the glass aquarium water. The product moment correlation coefficient showed a significant $(P<0.05)$ negative correlation between exposure time and different $L_{50}$ values. The $t$ ratio was $>1.96$, heterogeneity factor was $<1.0$, and the $g$ value was $<0.5$ at all probability levels. $L C L$, Lower confidence limit; UCL, upper confidence limit. Slope value is reported as mean \pm SEM.

\begin{tabular}{|c|c|c|c|c|c|}
\hline \multirow{2}{*}{$\begin{array}{l}\text { Exposure } \\
\text { time }\end{array}$} & \multirow[t]{2}{*}{ Bark extracts } & \multirow{2}{*}{$\begin{array}{c}\text { Lethal } \\
\text { concentration } \\
\text { LC }_{50} \\
(\mathrm{mg} / \mathrm{l})(\mathrm{w} / \mathrm{v})\end{array}$} & \multicolumn{2}{|c|}{ 95\% Confidence limits } & \multirow[t]{2}{*}{ Slope value } \\
\hline & & & $\begin{array}{l}\mathrm{LCL} \\
(\mathrm{mg} / \mathrm{l})\end{array}$ & $\begin{array}{l}\mathrm{UCL} \\
(\mathrm{mg} / \mathrm{l})\end{array}$ & \\
\hline \multirow[t]{4}{*}{$24 \mathrm{~h}$} & Lyophilized water extract & 34.5 & 27.2 & 50.8 & $1.94 \pm 0.34$ \\
\hline & Lyophilized boiled water extract & 42.5 & 32.8 & 68.3 & $2.10 \pm 0.39$ \\
\hline & Ethanolic extract & 4.9 & 3.6 & 8.0 & $1.22 \pm 0.27$ \\
\hline & Purified & 0.87 & 0.79 & 1.0 & $3.93 \pm 0.77$ \\
\hline \multirow[t]{4}{*}{$48 \mathrm{~h}$} & Lyophilized water extract & 20.1 & 16.3 & 25.7 & $1.83 \pm 0.29$ \\
\hline & Lyophilized boiled water extract & 27.3 & 21.4 & 39.0 & $1.65 \pm 0.29$ \\
\hline & Ethanolic extract & 2.4 & 1.7 & 3.2 & $1.43 \pm 0.26$ \\
\hline & Purified & 0.72 & 0.64 & 0.81 & $3.39 \pm 0.73$ \\
\hline \multirow[t]{4}{*}{$72 \mathrm{~h}$} & Lyophilized water extract & 13.5 & 10.6 & 16.6 & $1.87 \pm 0.28$ \\
\hline & Lyophilized boiled water extract & 18.0 & 14.5 & 22.7 & $1.83 \pm 0.28$ \\
\hline & Ethanolic extract & 1.2 & 0.54 & 1.6 & $1.33 \pm 0.27$ \\
\hline & Purified & 0.59 & 0.50 & 0.65 & $4.07 \pm 0.75$ \\
\hline \multirow[t]{4}{*}{$96 \mathrm{~h}$} & Lyophilized water extract & 9.1 & 6.4 & 11.6 & $1.68 \pm 0.27$ \\
\hline & Lyophilized boiled water extract & 11.0 & 7.6 & 14.2 & $1.47 \pm 0.26$ \\
\hline & Ethanolic extract & 0.94 & 0.61 & 1.2 & $1.65 \pm 0.29$ \\
\hline & Purified & 0.52 & 0.44 & 0.58 & $5.10 \pm 0.82$ \\
\hline
\end{tabular}


der of the ethanolic bark extract against Lymnaea acuminata were $34.5 \mathrm{mg} / \mathrm{l}$ and $4.9 \mathrm{mg} /$ 1, respectively. The lyophilized powder of the boiled aqueous extract of bark was also toxic (24-h $\left.\mathrm{LC}_{50}: 42.5 \mathrm{mg} / \mathrm{l}\right)$ against $L$. acuminata. The purified fraction obtained by column chromatography was more toxic (24-h LC $\mathrm{L}_{50}: 0.87 \mathrm{mg} / \mathrm{l}$ ) than other bark preparations. There was a significant negative correlation between the $\mathrm{LC}_{50}$ of different bark preparations and exposure periods (Table $1)$. No mortality was observed in a fish $(C$. fasciatus) population exposed to the same concentrations as used in the treatments against the snail L. acuminata.

The slope values were steep and the results were found to be within the $95 \%$ confidence limits of $\mathrm{LC}_{50}$. The $t$-ratio was higher than 1.96 and the heterogeneity factor was less than 1.0. The g values were less than 0.5 at all probability levels (Table 1).

The present results clearly indicate that the bark of Nerium indicum is an important source of a botanical molluscicide. The toxicity study revealed that the toxic component of Nerium indicum bark is soluble both in water and ethanol. The bioactive principle present in the bark is thermostable since there was no significant decrease in the molluscicidal activity of the boiled bark extract. Guzman and Ambros (8) observed that the aqueous extract of Nerium indicum bark is an effective insecticide against Blatta orientalis. Glycosides, steroids and terpenoids have been isolated from different parts of Nerium indicum (9). The toxic effect of different bark preparations may be due to the active glycoside neriodonin or neriodonein (10).

A comparison of the molluscicidal activity of the purified bark fraction (by column elution) with that of synthetic molluscicides clearly demonstrates that the purified bark fraction is more potent. Thus, the $96-\mathrm{h} \mathrm{LC}_{50}$ values of mexacarbate $(1.7 \mathrm{ppm})$, formothion (8.5 ppm), phorate (15.0 ppm) and fenvalerate (1.1 ppm) against Lymnaea acuminata are higher than those of purified bark (0.52 ppm). The molluscicidal activity of purified bark (24-h $\mathrm{LC}_{50}: 0.87 \mathrm{mg} / \mathrm{l}$ ) is about 23 times higher than that of the standard molluscicide niclosamide (24-h $\mathrm{LC}_{50}$ against $L$. acuminata: $11.8 \mathrm{ppm})$ (5).

The molluscicidal activity of purified bark is less pronounced than that of Nerium indicum latex (24-h $\mathrm{LC}_{50}$ against L. acuminata: $0.188 \mathrm{ppm}$ ) (4). The concentration range of latex effective against $L$. acuminata snails is toxic to the fish $C$. fasciatus (4), whereas the concentration range of bark effective against $L$. acuminata snails is not toxic to $C$. fasciatus, i.e., the use of bark in aquatic environments is safer than the use of latex.

The steep slope values indicate that a small increase in the dose of different treatments given in Table 1 caused high snail mortality. A $t$-ratio value greater than 1.96 indicates that the regression is significant. Heterogeneity factor values lower than 1.0 denote that in the replicate tests of random samples the concentration-response curves would fall within the $95 \%$ confidence limits and thus the model fits the data adequately. The index of significance of the potency estimation $g$ indicates that the value of the mean is within the limits at all probability levels $(90,95,99)$ since it is less than 0.5 .

We conclude that Nerium indicum bark extract may be used as a potent molluscicide since the concentrations used to kill $L$. acuminata snails were not toxic for $C$. fasciatus. The mechanism by which these bark extracts cause snail death is not exactly known and will require further studies for elucidation. 


\section{References}

1. Singh O \& Agarwal RA (1981). Toxicity of certain pesticides to two economic species of snails in Northern India. Journal of Economic Entomology, 74: 568-571.

2. Agarwal RA \& Singh DK (1988). Harmful gastropods and their control. Acta Hydrochimica et Hydrobiologica, 16: 113-138.

3. Singh A, Singh DK, Misra TN \& Agarwal RA (1996). Molluscicides of plant origin. Biological Agriculture and Horticulture, 13: 205-252.

4. Singh DK, Singh A \& Agarwal RA (1993). Nerium indicum, a potent molluscicide of plant origin. Journal of Medical and Applied Malacology, 5: 93-95.
5. Singh DK \& Agarwal RA (1984). Correlation of the anticholinesterase and molluscicidal activity of the latex of Euphorbia royleana Bioss. on Lymnaea acuminata. Journal of Natural Products, 47: 702-705.

6. Russell RM, Robertson JL \& Savin NE (1977). POLO: A new computer program for probit analysis. Bulletin of the Entomological Society of America, 23: 209213.

7. Sokal RR \& Rohlf FJ (1973). Introduction to Biostatistics. W.H. Freeman and Co., San Francisco, 271-273.

8. Guzman RS \& Ambros FA (1992). Effectiveness of Nerium indicum as insecticide to the house pest Blatta orientalis (cockroaches). 7th Asian Symposium on Medicinal Plants, Spices and Natural Products (ASOMPS VII), Manila, 2 (Abstract).

9. Siddiqui $S$, Siddiqui $B S$, Begum $S$ \& Hafeez F (1990). Chemical constituents of Nerium oleander. Pakistan Journal of Scientific and Industrial Research, 33: 127-141.

10. Anonymous (1991). The Wealth of India, Raw Materials. Vol. VII. Publications and Information Directorate, CSIR, New Delhi, 15-17. 